\title{
Periostin in Periodontics: A Brief Insight
}

\author{
Dhawal Rajendra Mody ${ }^{1}$, Vrushali Lathiya', Kamalkishor Mankar ${ }^{3}$ \\ ${ }^{1,3}$ Associate Professor, ${ }^{2}$ Assistant Professor, \\ Dept. of Periodontics, VSPMs Dental College \& Research Centre, Hingna Road, Nagpur-440019
}

Corresponding Author: Dhawal Rajendra Mody

\begin{abstract}
The prime objective of the periodontal treatment is to re-establish the lost periodontal tissue by forming new attachment of periodontal ligament, cementum and the alveolar bone. Periostin is a matricellular protein with its structure closely resembling to that of Drosophila fasciclin. It is expressed in the periodontal ligament, periosteum, alveolar bone, adipose tissue as well as skeletal tissue and has a key role in role in tooth development. This protein molecule has a striking similarity to the molecule beta ig-h3 which is induced by transforming growth factor beta (TGF-beta), promotes the adhesion and spreading of fibroblasts and aids in collagen formation. It is possibly involved in the post surgical regeneration of periodontal hard and soft tissues. Periostin is also linked to dental papilla cells and is associated with hard tissue formation stages of tooth development. This mini review focuses on the various aspects of periostin related to maintenance and development of collagen rich connective tissues around the teeth.
\end{abstract}

Key words: Periostin, Periodontal ligament, Periodontal regeneration, Alveolar bone.

\section{INTRODUCTION}

Periodontal ligament incorporates a remarkable capacity for renewal and repair, playing a pivotal role in periodontal regeneration ${ }^{1}$. Additionally, the fibroblastic PDL cells are thought to be multipotent cells which may be a source of osteoblasts for continued remodelling of alveolar bone within the jaws ${ }^{2}$. Periostin, originally called osteoblasts-specific factor-2 (Osf-2), was first isoloted from the mouse MC3T3-E1 osteoblastic cell line and is reported to support MC3T3-E1 cell attachment and spreading. Since this protein is closely associated with the periodontal ligament and the periosteum of the alveolar bone, it was named as Periostin. Periostin has structural similarity to Drosophila fascilin-1, a haemophilic adhesion protein that is involved in the neuron growth cone guidance $^{3}$. This protein was expected to function in tooth and bone remodeling under mechanical stress, since both the periodontal ligament and periosteum are sites sensitive to mechanical stress by mastication and physical exertion, respectively. Such stress induces remodeling of the periodontal ligament and parietal bone. ${ }^{4}$ Periostin is categorized as one of the matricellular proteins: a class of extracellular matrix (ECM) - related molecules defined by their ability to modulate cell-matrix interactions. ECM is not only secreted locally by cells and organized into a scaffold to support cells, tissues, and organs but is also now known to provide signals and regulating their phenotypes in terms of morphology and differentiation. ${ }^{5}$ Extracellular matrix components like type I collagen and periostin in cranial neural crest cells are associated with differentiation of the hard and soft palates along the anterior-posterior axis during pathogenesis in the developmental stage via transforming growth factor (TGF)- $\beta$ signaling pathway. ${ }^{6}$ 
LIST OF KNOWN MATRICELLULAR PROTEINS

Matricellular proteins

\begin{tabular}{|l|l|}
\hline \multicolumn{1}{|c|}{ Bone sialoprotein } & \multicolumn{1}{c|}{ Periostin } \\
\hline $\mathrm{CCN}_{2}$ & SPARC (Osteonectin) \\
\hline $\mathrm{Cyr}_{1}$ & Tenascin-C \\
\hline Galectin 1,2,3,4,8 and 9 & Thrombospondin-1 and 2 \\
\hline Nov & WISP-1,2 and 3 \\
\hline Osteopontin & \\
\hline
\end{tabular}

MOLECULAR MECHANISM OF PERIOSTIN IN THE PERIODONTIUM

Periostin is involved at sites of cellto-matrix interactions, serving as the adhesive equipment for bearing mechanical force, including tooth eruption, and transducing the occlusal force that activates the latent TGF beta, which in turn enhances periostin expression. ${ }^{7}$ Periostin knockout mice show a defect in the structure of their incisors followed by eruption deficiency, though the structure of their molars was relatively normal. In the incisors, nondigested collagen fibrils appear, which is now explained by the low activity of MMPs, since periostin is known to efficiently activate the secretion of MMP 2 and MMP 9 from human epithelial cells and mouse macrophages. $^{8}$

Periostin acts on type I collagen production inside the cell, where periostin forms a meshwork, structure with fibronectin to constitute a scaffold for the cross-linking of type-I collagen. ${ }^{9}$ This crosslinking is effected by periostin in association with BMP-1 to activate lysyl oxidase for enhancement of cross-linking activity inside the cell. ${ }^{10}$

\section{FUNCTIONS OF MATRICELLULAR PROTEINS}

Periostin is involved in two major functions, one is cell intrinsic function of fibrillogenesis and other is cell migration which takes place outside the cell. By interacting with fibronectin, tenascin- $\mathrm{C}$ and bone morphogenetic protein -1 through the Fas-1 domain, it promotes the proteolytic activation of lysyl oxidase for the cross linking of collagen. ${ }^{11}$ It also plays a pivotal role in facilitating cell motility by triggering the actin/myosin contractile machinery.

Periostin has been shown to play a crucial role in maintaining periodontal ligament integrity and takes active part in its regeneration.

Well Known effects of matricellular proteins on cell physiology are:

\begin{tabular}{|c|}
\hline Cell adhesion \\
\hline Proliferation \\
\hline Migration \\
\hline Apoptosis \\
\hline Biomineralization \\
\hline ECM synthesis \\
\hline Differentiation \\
\hline Collagen fibrillogenesis \\
\hline Growth factor production \\
\hline
\end{tabular}

\section{CLINICAL APPLICATIONS}

Recently a diagnostic trial has been started in the pulmonary diseases, as periostin was shown to be a good biomarker of asthma. A trial of treatment with recombinant periostin in a preclinical infarct has also been started; since periostin is essential for cardiac repairing after an acute myocardial infarction. Cho et al. transferred periostin-overexpression mesenchymal cells, resulting in improved cardiac function. ${ }^{12}$

Thus it may be stated that antiperiostin antibody or recombinant periostin may promote further development of periostin for these applications in dental field.

\section{CONCLUSION}

The PDL is a soft connective tissue interposed between the roots of the teeth and alveolar bone, and it is characterized by rapid turn-over and a high remodelling capacity, which give it adaptability, maintaining a constant width despite being exposed to rapidly changing physical forces such as mastication, speech and orthodontic tooth movement. Periostin protein continues to be highly expressed in the developing dental follicle and in the adult mouse periodontium, particularly at the sites of hard-soft tissue interfaces. Thus the above data highlights the importance of periostin 
in maintaining the structural integrity of the periodontium during occlusal function.

\section{Acknowledgement: None}

\section{Conflict of Interest: None}

\section{Source of Funding: None}

\section{Ethical Approval: Not Applicable}

\section{REFERENCES}

1. Beertsen W, McCulloch CA, Sodek J. The periodontal ligament: a unique multifunctional connective tissue. Periodontol 2000 1997; 13: 20-40.

2. McCulloch CA, Bardin S. Role of fibroblasts in periodontal physiology and pathology. J Periodontal Res 1991; 26:144154.

3. Agnieszka Kruzynska-Frejtag' Jian Wang, et al. Periostin is expressed within the developing teeth at the sites of epithelialmesenchymal interaction. Dev Dyn 2004; 229(4): 857-868.

4. Horiuchi K, Amizuka N, Takeshita S, et al. Identification and characterization of a novel protein, periostin with restricted expression to periosteum and periodontal ligament and increased expression by transforming growth factor $\beta$. J Bone Miner Res1999; 14:1239-1249

5. Ganburged G, Suda N, Salto M, Yamazaki $\mathrm{Y}$ et al. Dilated capillaries, disorganized collagen fibres and differential gene expression in periodontal ligaments of hypomorphic fibrillin-1 mice. Cell Tissue Res 2010: 341:381-395.
6. Oka K, Honda MJ, Tsuruga E et al. Roles of collagen and periostin expression by cranial neural crest cells during soft palate development. J Heterocyst Chem 2012; 60:57-68.

7. Rios $\mathrm{H}$, Koushik SV, Wang $\mathrm{H}$, et al. Periostin null mice exhibit dwarfism, incisor enamel defects, and an early-onset periodontal disease-like phenotype. Mol Cell Biol 2005; 25:11131-11144.

8. Hakuno D, Kimura N, Yoshioka M,et al. Periostin advances atherosclerotic and rheumatic cardiac valve degeneration by inducing angiogenesis and MMP production in human and rodents. J Clin Invest 2010; 120:2292-2306.

9. KII 1, Nishiyama $\mathrm{T}$, $\mathrm{Li} \mathrm{M}$, et al. Incorporation of tenascin-C into extracellular matrix by periostin underlies extracellular meshwork architecture. J Biol Chem 2010; 285:2028-39.

10. Maruhashi T, Kii L, Saito $M$, et al. Interaction between periostin and BMP-1 promotes proteolytic activity of lysyl oxidase. J Biol Chem 2010; 285:1329413303.

11. Du J, Li M. Functions of Periostin in dental tissues and its role in periodontal tissues' regeneration. Cellular and Molecular Life Sciences: CMLS. 2017 Dec;74(23):42794286.

12. Issei Takayama, Kudo A. Periostin in dental science .Japanese Dental J Review 2012: 48, 92-98.

How to cite this article: Mody DR, Lathiya V, Mankar K. Periostin in periodontics: a brief insight. International Journal of Science \& Healthcare Research. 2021; 6(2): 147-149. DOI: https://doi.org/10.52403/ijshr.20210426 